\title{
BED UTILIZATION IN CARDIO VASCULAR AND THORACIC SURGERY WARD
}

\author{
Ishtyak Ahmed Mir' 1 A. G. Ahangar ${ }^{2}$ \\ ${ }^{1}$ Lecturer, Department of Cardiovascular and Thoracic Surgery, SSH, GMC, Jammu. \\ 2Director, NEIGRIHMS, Shilliong, Meghalaya, India.
}

ABSTRACT: BACKGROUND: Of all the subsystems of a hospital, inpatient care occupies prime place in terms of resource consumed, use of specialized technical man power, technology and skill. In spite of the huge investment of money, material and the manpower at times even the basic needs of patients are not met.

AIMS: The study was conducted, to observe the average length of stay (ALS) of patients in cardio vascular and thoracic Surgery (CVTS) ward, and to find out the bed occupancy rate.

METHODS: The admission and discharge record of all the patients was recorded from the report books, hospital files of all the patients were checked to know complete biodata. Medical record section was consulted and admission discharge register/files were recorded to know the symptomatology, clinical findings, diagnosis and the management thereof. Mortality and morbidity was recorded from admission files.

RESULTS: A total of 732 patients were admitted on a bed complement of 11712 days having 8639 bed days. $84.28 \%$ of the patients underwent surgical procedures. Daily average beds occupied were 23.60 beds per day, average length of stay was 11.23 days, and $73.76 \%$ was the bed occupancy rate.

CONCLUSION: Patients having major operations had more length of stay compared to patients who were admitted after pre anesthetic checkup and full planning from outdoor departments. Preadmission evaluation, pre anesthetic checkup and preventing post-operative morbidity decrease length of stay.

KEYWORDS: Bed Complement, Bed Days, Average Length of Stay, Bed Occupancy Rate.

HOW TO CITE THIS ARTICLE: Ishtyak Ahmed Mir, A. G. Ahangar. "Bed Utilization in Cardio Vascular and Thoracic Surgery Ward". Journal of Evolution of Medical and Dental Sciences 2015; Vol. 4, Issue 91, November 12; Page: 15615-15618,

DOI: $10.14260 /$ jemds/2015/2244.

INTRODUCTION: Of all the subsystems of a hospital, inpatient care occupies prime place in terms of comfort, basic needs, primary care, specialized investigation, specific diagnosis, prompt and precise treatment. India is having an average bed availability of about 0.85 beds per 1000 population as compared to recommended norm of 1.0 bed per 1000 population. $^{1}$ Different indices are used in assessment of hospital utilization, average length of stay (ALS) is one of the parameters frequently used to assess the utilization of beds and thereby the efficiency of a hospital unit, it gives the average stay in days per admitted patient. ${ }^{2}$

The average length of stay and its effective control could be judged from the simple fact that decrease of average length of stay just by one day on all the beds in country can mobilize a bed capacity equivalent to making available approximately 41000 additional beds in a year. ${ }^{3}$ Large percentage of bed complement is occupied by the operated patients, more so by patients having undergone major surgeries. The study was conducted to find out the reasons for increased lengths of stay, and bed occupancy rate. The retrospective study included all the patients admitted in the

Financial or Other, Competing Interest: None.

Submission 27-10-2015, Peer Review 28-10-2015,

Acceptance 31-10-2015, Published 10-11-2015.

Corresponding Author:

Dr. Ishtyak Ahmed Mir,

C-1, Old Medical Enclave, Near K. C. Cinema,

Jammu-180001, J \& K, India.

E-mail: ishtyak_mir@rediffmail.com

DOI:10.14260/jemds/2015/2244. department of cardiovascular and thoracic surgery over a period of one year.

A total of 732 patients were admitted on a bed complement of 11712 days having 8639 bed days. Patients having undergone major surgeries, and those who developed postoperative complications had increased length of stay. Without compromising the patient safety, pre admission evaluation, anesthetic checkup, other specialty clearance should be done from outdoor patient department only, in addition preventing postoperative complications helps decrease hospital stay.

MATERIALS AND METHODS: The study was conducted over a period of one year in the department of Cardio Vascular and Thoracic Surgery (CVTS) in a tertiary care hospital with functional bed compliment of 32 . In view of inclement weather conditions, all the parameters were assessed with reference to all the months i.e. April to march. The department performs all types of thoracic, vascular, and majority of cardiac surgeries. It has full backing of postoperative ward, intensive care services, and besides 10 operations days a week, emergency operation facilities are available round the clock.

All the patients admitted in the department of CVTS irrespective of age, sex, race, diagnosis and management were included in the study. The ward is located in the first floor of the hospital, and fulfills all the requirements as per norms laid down by medical council of India (MCI), with regard to space, staffing, and administration. The department has adequate faculty staff besides regular/rotating senior and junior Residents. The ancillary and auxiliary facilities are available in the ward. 
The admission and discharge record of all the patients was recorded from the report books, hospital files of all the patients were checked to know complete biodata.

Medical record section was consulted and admission discharge register/files were recorded to know the symptomatology, clinical findings, diagnosis and the management there of Mortality and morbidity was recorded from admission files. A complete census with regard to admitted patients, patients turn over, transferred, new admissions, discharge and total bed occupied were recorded twice daily, and the observations were made by the census figure of the morning report.

The data was obtained for the information of, bed complement, total daily admissions/discharges, daily total number of patient day, and daily total number of vacant beds.

The information so obtained was used to derive bed utilization, with regard to, average length of stay, daily average beds occupied, and bed occupancy rate.

That the total number of the unit bed constitutes the bed compliment and is designated as " $\mathrm{B}$ " admissions refers to the number per year of the acceptances by a hospital of a patient who is to receive medical treatment. Bed days or patient days is the unit of measure denoting the services rendered to one inpatient in the hospital census between one day and succeeding day, the annual number of hospitalized patients days is designated " $\mathrm{H}$ ", and the daily average of beds occupied are designated "N" and will be H/366.

The average of length of stay was calculated by:

a) Total number of bed days in the year $(\mathrm{H})$ divided by number of discharges (D)+Deaths in a year

(d) $=H / D+d$.

b) ALS- total number of bed days in the year $(\mathrm{H})$ divided by the number of admissions in the same year (A), $(\mathrm{L}=\mathrm{H} / \mathrm{A})$.

The bed occupancy rate was calculated by the formula

$$
\begin{aligned}
& \text { "O" }=\mathrm{N} / \mathrm{B} \times 100 \text {, whereas } \mathrm{O} \text { is the bed occupancy rate } \\
& \mathrm{B}=\times 100
\end{aligned}
$$

$\mathrm{H}=8639$ days, $\mathrm{H}$ is the total number of beds used for CVTS patients,

$\mathrm{B}=11712$ days, i.e. the total bed complement of CVTS ward.

RESULTS: A total of 732 patients were admitted on a bed complement of 11712 days, having 8639 bed days. Age of the patients ranged from 4 months to 96 years with 227 female patients. Majority of the patients were from the rural areas, and low socio economic status. Post traumatic injuries either because of road traffic accidents (RTA), fire arm injury (FAI) or assault was the common cause of admission (Table 1), besides chest wall/tracheal/pleural/diaphragmatic/sternal / carotid body/rib/and thymic tumors, patients with $\mathrm{A} \mathrm{V}$ malformations, arterial stenosis, lymphoma's, PVOD, hemangioma, Myxoma, retrosternal thyroids, acute and chronic limb ischemia, cervical ribs, venous ulcers, constrictive pericarditis, and thymic pathologies were operated.

The functional bed complement of the ward was 32 beds, and the total bed complement for the given period of 12 months 366 days was 11712 days. Maximum admissions (Table 2), were in the month of July $10.51 \%$ and the least in
February $04.91 \%$, most of the patients $10.10 \%$ were discharged in the month of April and the least in the month of February $04.09 \%$.

July accounted for the maximum operations $09.01 \%$, overall mortality was $06.01 \%$. Highest number of bed days $10.20 \%$ were observed in the month of March and the lowest $06.08 \%$ in the month of November. Highest average length of 20 days was observed in the month of February, and the lowest of 09.22 days in the month of July.

Average length of stay (Table 3), was more in patients undergoing surgery for esophageal carcinoma 18.71 days, major heart operations, decortications, lung resections, surgery in bronchopleural fistula and vascular repairs after avulsion injuries, average length of stay was shortest 06.39 days in patients operated for patent ductus arteriosus. Average daily beds occupied were 23.60 beds, and average length of stay was 11.23 days. Bed occupancy rate was ideal in the month of September and March (Table 4). The overall bed occupancy rate was 73.76 percent.

COMMENTS: In a large general hospital 25 to $30 \%$ of patients are surgical and $50 \%$ of all admitted patients undergo some sort of surgery. ${ }^{4}$ ALS and bed occupancy rate are considered to measure hospital utilization, patients with increased length of stay have increased resource consumption.5-6 Majority of the patients were males and had no bearing on ALS, bed occupancy rate and these observations are in accordance to other studies. ${ }^{7}$ More patients in fifth through seventh decade of life may be one of the reasons for prolonged length of stay, it has been observed that advanced age is predictive of prolonged ALS.8-9 $12.43 \%$ of the patients having trauma is because of the increased incidence of road traffic accidents, falls and fire arm injuries. In patients with avulsion injuries, fractures and vascular anastomosis, length of stay increases, also a multispecialty approach that of CVTS, plastic, orthopedic and general surgeons are needed in these patients. ${ }^{10}$ more bed complement occupied by the esophagogastrectomy patients is because of post-operative complications, 3 of these patients stayed in the ward for 2 to 3 months. Hospital stay in patients with post lobectomy atelectasis is more than in patients without complications. ${ }^{11}$

Though socio economic status is one of the predictors of prolonged stay, factors like poor functional status, and co existing illness also have a bearing. ${ }^{12}$ Pre-operative evaluation, investigation, and pre anesthetic checkup decreased length of stay in some patients in present study, and is in conformity to the observation made by others. The variations in admissions, discharge, surgical procedures, bed complement, ALS, bed occupancy rate in some months of the year could be explained by the fact that because of the changing weather conditions, farming, influx of peoples, outdoor activities are limited or are more in some months, also the snow bound areas may remain cut of from the main hospital for some time, above all elective surgical patients may prefer operations in good weather.

The average length of stay per patient in CVTS ward was found to be 11.23 days, which is at variance to other studies, who observed ALS of 9.9 and 14 days. ${ }^{13}$ Though patients with major surgical procedures were found to have more ALS, a theoretical possibility that contaminated surgeries would have prolonged hospital stay, but poor post-operative outcomes are associated with prolonged length of stay. In Egypt the average length of hospital stay is about 14 days and in France about 20 days. ${ }^{14}$ Daily average bed occupancy of 
23.60 beds per day is at variance with other reported studies. of 29.87 beds per day. Every attempt should be made to extubate patients at the earliest, post-operative intubated patients have prolonged stay. ${ }^{15-16}$

Bed occupancy rate of $73.76 \%$ is at variance with other reported studies, an occupancy rate of less then $80 \%$ is considered uneconomical, and $80-85 \%$ occupancy is considered ideal for good quality of patient care and $100 \%$ of occupancy means over utilization which lead to fall in quality of care.7,17 It is a known fact that associated problems increase length of stay in hospitals. ${ }^{18}$ The limitations of the study are it provides the ALS and bed occupancy rate for all the patients admitted/operated in CVTS. If different diseases were analyzed separately the figures would have been quiet different, such that esophagectomy patients would have more ALS compared to patients operated for PDA.

In conclusion at least for elective operations, preadmission investigation, evaluation, interdepartmental consultations, management of associated diseases, pre anesthetic checkups, planning for proper approach in infected, elderly, pregnant, low socioeconomic group, immunocompromised, and associated diseases, should be done on outdoor basis only. Early suspicion, proper recognition and definitive treatment should be initiated for all the complications including in consultations with other specialties to reduce morbidity, mortality and hospital stay.

\section{BIBLIOGRAPHY:}

1. Census of India 2001/ 95-96 CBHI.

2. Katz NM, Ahmed SW, Clark BK, Wallace RB. "Predictors of length of hospitalization after cardiac surgery". Ann Thorac Surg 1985; 45: 656-660.

3. Kumar A; Parmar NK; Gupta AK. Average length of stay: A managerial tool for raising hospital productivity substantially, J Acad Hosp Admn 1991 Jan; 3 (1): 47-51.

4. Sakharkar BM. "Operation theatre suit" In Principals of hospital administration and planning. 1998 first edition; 14: $197-207$.

5. Llewelyn-Davies R, Macaulay HMC. Hospital planning and administration. WHO Monograph series No. 54. Geneva. 1966.

6. Tracie C. Collins, Jennifer Daley, William H Handerson, Shukri F Khuri. "Risk factors for prolonged length of stay after major elective surgery". Ann Surgery 1999 Aug; 230(2): 251-59.
7. Rosenfield R, Smith JM, Woods SE, Engel AM. Predictors and outcome of extended intensive care unit length of stay in patients undergoing coronary artery bypass graft surgery. J Card Surg 2006; 21: 146-150.

8. Cleary PD, Greenfield S, Mulley AG, Stephen G Pauker, Steven A Schroeder, Lewis Wexler, et al. "Variations in length of stay and outcomes for 6 medical and surgical conditions". JAMA 1991; 266: 73-79.

9. Greenfields S, Apolone G, McNeil BJ, Cleary PD. The importance of co existent disease in the occurrence of post-operative complications, one year recovery in patients undergoing total hip replacement. Co morbidity and outcome after hip replacement. Med Care 1993 Feb; 31(2): 141-54.

10. Gordon HS, Rosenthal GE. Impact of inter hospital transfers on outcomes in academic medical centre, implications for profiling hospital quality. Med Care 1996 Apr; 34 (4): 295- 309.

11. Korst RJ, Humphrey CB. Complete lobar collapse following pulmonary lobectomy, its incidence, predisposing factors, and clinical ramifications. Chest 1997 May; 111 (5): 1285-9.

12. Munoz E, Tortella BJ, Jaker M, Sakmyster M, Kanfsky P. Surgical resource consumption in an academic health consortium. Surgery 1994; 115(4): 411-416.

13. Kiran ER, Vijaya K. Utilization of beds in a tertiary care hospital. Journal of Association of Hospital Administration 2004; 15(2): 13-17.

14. Bridgman RF. The rural hospital its structure and organization. WHO, Geneva 1955; pp 58-61.

15. Waseem Qureshi, Ghulam Hassan. A five year retrospective study of bed utilization trends in a tertiary care teaching institution. JK Science 2014 Sep; 16(2): 11921.

16. Gross SB. Early extubation, preliminary experience in the cardiothoracic patient population. Am J Crit Care 1995 Jul; 4 (4): 262-6.

17. Michael Gillies, Renaldo Bellomo, Lauri Doolan, Brian Buxton. Bench to bed side review: Ionotropic drug therapy after adult cardiac surgery- a systematic literature review. Crit Care 2005; 9(3): 266-279.

18. Hein OV, Birnbaum J, Wernecke K, England M, Konertz W, Spies C. Prolonged intensive stay in cardiac surgery: risk factors and long term survival. Ann Thorac Surg 2006; 81: 880-885.

\begin{tabular}{|c|c|c|}
\hline Patient Admitted for & Number of Patients & Percentage \\
\hline Trauma Chest/Vascular & 91 & 12.43 \\
\hline Carcinoma esophagus & 77 & 10.51 \\
\hline Bronchogenic carcinoma & 67 & 09.15 \\
\hline Open Heart surgery & 55 & 07.51 \\
\hline Hydatid Lung & 44 & 06.01 \\
\hline Pneumothorax & 39 & 05.32 \\
\hline Fibrothorax & 36 & 04.91 \\
\hline CHD-PDA & 23 & 03.14 \\
\hline Empyema & 19 & 02.59 \\
\hline \multicolumn{2}{|c|}{ Table 1: Major ailments for which } \\
\hline
\end{tabular}




\begin{tabular}{|c|c|c|c|c|}
\hline $\begin{array}{c}\text { Month } \\
\text { of the } \\
\text { Year }\end{array}$ & $\begin{array}{c}\text { No. of } \\
\text { Admissions } \\
\text { (\% age) }\end{array}$ & $\begin{array}{c}\text { No. of } \\
\text { Operations } \\
\text { (\% age) }\end{array}$ & $\begin{array}{c}\text { No. of } \\
\text { Discharges } \\
\text { (\% age) }\end{array}$ & $\begin{array}{c}\text { No. of } \\
\text { Deaths } \\
\text { (\% age) }\end{array}$ \\
\hline April & $56(07.65)$ & $45(07.29)$ & $74(10.20)$ & $02(04.54)$ \\
\hline May & $71(09.69)$ & $62(10.04)$ & $63(08.68)$ & $03(06.81)$ \\
\hline June & $66(09.01)$ & $48(07.77)$ & $70(09.65)$ & $04(09.09)$ \\
\hline July & $77910.51)$ & $66(10.69)$ & $73(10.06)$ & $06(13.63)$ \\
\hline August & $72(09.24)$ & $61(09.88)$ & $62(08.55)$ & $05(11.36)$ \\
\hline September & $71(09.69)$ & $58(09.40)$ & $67(09.24)$ & $05(11.36)$ \\
\hline October & $54(07.37)$ & $55(08.91)$ & $63(08.68)$ & $03(06.81)$ \\
\hline November & $58(07.92)$ & $43(06.96)$ & $66(09.10)$ & $01(02.27)$ \\
\hline December & $61(08.33)$ & $55(08.99)$ & $70(09.65)$ & $05(11.36)$ \\
\hline January & $49(06.69)$ & $34(05.510$ & $43(05.93)$ & $03(06.81)$ \\
\hline February & $36(04.91)$ & $27(04.37)$ & $30(04.13)$ & $02(04.54)$ \\
\hline March & $61(08.33)$ & $63(10.21)$ & $44(05.51)$ & $05(11.36)$ \\
\hline \multicolumn{7}{|c|}{ Table 2: Showing Number of Admissions, Operations, } \\
Discharges and Deaths Apr 04 to Mar 05 \\
\hline
\end{tabular}

\begin{tabular}{|c|c|c|c|c|c|}
\hline $\begin{array}{c}\text { Month of } \\
\text { Study }\end{array}$ & $\begin{array}{c}\text { Bed } \\
\text { Days }\end{array}$ & $\begin{array}{c}\text { Bed } \\
\text { Complement }\end{array}$ & $\begin{array}{c}\text { No. of } \\
\text { Discharges }\end{array}$ & $\begin{array}{c}\text { No. of } \\
\text { Deaths }\end{array}$ & $\begin{array}{c}\text { Average Length } \\
\text { of Stay Days }\end{array}$ \\
\hline April & 745 & 960 & 74 & 2 & 09.80 \\
\hline May & 810 & 992 & 63 & 3 & 12.27 \\
\hline June & 692 & 960 & 70 & 4 & 09.35 \\
\hline July & 729 & 992 & 73 & 6 & 09.22 \\
\hline August & 774 & 992 & 62 & 5 & 11.55 \\
\hline September & 815 & 960 & 67 & 5 & 11.31 \\
\hline October & 662 & 992 & 63 & 3 & 10.03 \\
\hline November & 526 & 960 & 66 & 1 & 07.85 \\
\hline December & 814 & 992 & 70 & 35 & 10.85 \\
\hline January & 550 & 992 & 43 & 3 & 11.95 \\
\hline February & 640 & 928 & 30 & 2 & 20.00 \\
\hline March & 882 & 992 & 44 & 5 & 18.00 \\
\hline \multicolumn{7}{|r|}{ Table 3: Average length of stay (ALS) in days on monthly basis } \\
\hline
\end{tabular}

\begin{tabular}{|c|c|c|c|}
\hline $\begin{array}{c}\text { Month of } \\
\text { Study }\end{array}$ & $\begin{array}{c}\text { Bed Days } \\
\text { (H) }\end{array}$ & $\begin{array}{c}\text { Bed Complement } \\
\text { Days (B) }\end{array}$ & $\begin{array}{c}\text { Bed Occupancy } \\
\text { Rate Percentages }\end{array}$ \\
\hline April & 745 & 960 & 77.60 \\
\hline May & 810 & 992 & 81.65 \\
\hline June & 692 & 960 & 72.08 \\
\hline July & 729 & 992 & 78.48 \\
\hline August & 774 & 992 & 84.89 \\
\hline September & 815 & 960 & 66.73 \\
\hline October & 662 & 992 & 54.79 \\
\hline November & 526 & 960 & 82.05 \\
\hline December & 814 & 992 & 68.44 \\
\hline January & 550 & 992 & 88.91 \\
\hline February & 640 & 928 & 992 \\
\hline March & 882 & Table 4: Monthly Bed Occupancy Rate (Percent) \\
\hline \multicolumn{4}{|c|}{}
\end{tabular}

